\title{
Qualidade de melões 'Louis' armazenados em quatro temperaturas
}

\author{
Quality of 'Louis' melons stored under four storage temperatures
}

\author{
Cristiane Maria Ascari Morgado ${ }^{I}$ Claudia Fabrino Machado Mattiuz ${ }^{\text {II }}$ \\ Ana Carolina Muniz ${ }^{\text {III }}$ Florence Charles ${ }^{\text {IV }}$ Ben-Hur Mattiuz
}

\section{RESUMO}

Este trabalho teve como objetivo estabelecer a melhor temperatura para a conservação de melões 'Louis'. Os frutos foram armazenados sob condição de ambiente $\left(22 \pm 2^{\circ} \mathrm{C}\right.$ e $80 \pm 5 \%$ UR), sob refrigeração $\left(3 \pm 1^{\circ} \mathrm{C}\right.$ e $80 \pm 5 \%$ UR; $6 \pm 1{ }^{\circ} \mathrm{C}$ e $80 \pm 5 \%$ UR; e $9 \pm 1{ }^{\circ} \mathrm{C}$ e $80 \pm 5 \%$ UR) e avaliados quanto à coloração e firmeza da polpa, teores de sólidos solúveis, acidez titulável, atividade das enzimas peroxidase, polifenoloxidase, poligalacturonase e pectinametilesterase e perda de massa fresca. Os melões 'Louis' armazenados a $22^{\circ} \mathrm{C}$ apresentaram maior redução nos teores de sólidos solúveis e acidez titulável, além de apresentarem maior atividade da enzima poligalacturonase, com conservação por até 18 dias. Os frutos armazenados a $6^{\circ} \mathrm{C}$ mantiveram a qualidade comercial durante 25 dias de armazenamento, apresentando os maiores teores de sólidos solúveis e menor atividade das enzimas peroxidase e poligalacturonase.

Palavras-chave: armazenamento refrigerado, vida de prateleira, Cucumis melo L.

\section{ABSTRACT}

This research aimed to establish the best temperature for the conservation of 'Louis' melons. Fruit were stored under ambient condition $\left(22^{\circ} \mathrm{C}\right.$ and $\left.80 \% \mathrm{RH}\right)$ and under refrigeration $\left(3^{\circ} \mathrm{C}-80 \% \mathrm{RH}, 6^{\circ} \mathrm{C}-90 \% \mathrm{RH} e\right.$ $9^{\circ} \mathrm{C}-80 \% \mathrm{RH}$ ) and evaluated for color and resistance of pulp, soluble solids, titratable acidity content, peroxidase, polyphenol oxidase, polygalacturonase and pectin methyl esterase activity and weight loss. 'Louis' melons at $22^{\circ} \mathrm{C}$ showed greater reduction in soluble solids and titratable acidity content, and had higher activity of the enzyme polygalacturonase, culminating in conservation for 18 days. Melons stored at $6^{\circ} \mathrm{C}$ preserved the shelf-life for 25 days, showed the highest soluble solids and lower activity of peroxidase and polygalacturonase.

Key words: refrigeration storage, shelf-life, Cucumis melo $L$.

\section{INTRODUÇÃO}

O meloeiro (Cucumis melo L.) pertence à família das Cucurbitáceas, apresenta frutos de formato variável (redondo, oval ou alongado), casca lisa, enrugada ou rendilhada, pesando de um a quatro quilos. A coloração da polpa pode ser branca, amarelada, esverdeada, laranja ou salmão. A polpa deste fruto é constituída de $90 \%$ de água e contém vitaminas A, C e E, além de sais minerais e elevado teor de açúcares, cujo gosto adocicado o torna apreciado pelos consumidores (MOREIRA et al., 2009).

Os frutos do híbrido Louis, pertencentes ao grupo Net Melon, apresentam formato esférico, casca com coloração verde clara, intensamente reticulada e polpa esverdeada. É um híbrido resistente a oídio e à fusariose, possui teor de sólidos solúveis em torno de $15-16^{\circ}$ Brix e frutos com peso médio de 1,5kg (TAKII SEED, 2010),

'Centro Universitário de Rio Preto (UNIRP), São José do Rio Preto, SP, Brasil.

"Escola Superior de Agricultura "Luiz de Queiroz" (ESALQ), Universidade de São Paulo (USP), Piracicaba, SP, Brasil.

IIIPrograma de Pós-graduação em Agronomia (Produção Vegetal), Departamento de Tecnologia, Faculdade de Ciências Agrárias e Veterinárias (FCAV), Universidade Estadual Paulista “Julio de Mesquita Filho” (UNESP), Jaboticabal, SP, Brasil.

IV Laboratoire Physiologie des Fruits et Légumes - EA 4279, Université d'Avignon et des Pays de Vaucluse, Avignon, France.

vepartamento de Tecnologia, FCAV, UNESP, Via de Acesso Prof. Paulo Donato Castellane, s/n, 14884-900, Jaboticabal, SP, Brasil. E-mail: benhur@fcav.unesp.br. Autor para correspondência. 
mas apresentam baixa conservação pós-colheita, por serem climatéricos e apresentarem, depois da colheita, aumento na atividade metabólica, com aumento na taxa respiratória, o que reduz sua vida útil (CHITARRA \& CHITARRA, 2005).

Assim, os principais entraves ao prolongamento da qualidade pós-colheita desse tipo de melão estão associados à sua rápida velocidade de respiração e senescência, fazendo-se necessário o uso de tecnologias, como a refrigeração.

O armazenamento refrigerado é uma ferramenta importante para o prolongamento da vida útil de frutos. Possibilita a comercialização em locais distantes da produção, usando-se meios de transporte mais demorados, cujo frete tem custo, geralmente, menor, melhorando a competitividade no mercado internacional (LIMA et al., 2006).

FILGUEIRAS et al. (2000) estabeleceram que o armazenamento de melões é feito, geralmente, sob temperatura de $4-6^{\circ} \mathrm{C}$ e $90-95 \%$ UR. Entretanto, o conhecimento do comportamento pós-colheita de novos híbridos é muito limitado, exigindo estudos que permitam melhorar a conservação de seus frutos na pós-colheita, de forma a ampliar a oferta desse produto no mercado consumidor (MORAIS et al., 2004).

Diante do exposto, objetivouse estabelecer a melhor temperatura de armazenamento para a conservação de melões do híbrido 'Louis'.

\section{MATERIAL E MÉTODOS}

Foram utilizados melões rendilhados 'Louis', colhidos no estádio de maturacão fisiológica, em propriedades comerciais de Itápolis - SP. Os frutos foram acondicionados em caixas de papelão apropriadas e transportados por 70km até o Laboratório de Tecnologia dos Produtos Agrícolas da FCAV/UNESP, em Jaboticabal - SP, onde foram novamente selecionados quanto ao tamanho, cor e ausência de injúrias, visando a maior uniformidade do lote. Após a seleção, os frutos foram higienizados, imersos em solução comercial a base de composto orgânico clorado (Sumaveg $\left.{ }^{\circledR}\right)(6,66 \mathrm{~g}$ $\mathrm{L}^{-1}$ de água), correspondente a $200 \mathrm{mg} \mathrm{L}^{-1}$ de cloro ativo, por 10 minutos.

Os melões foram armazenados sob quatro condições: $22 \pm 2{ }^{\circ} \mathrm{C}$ e $80 \pm 5 \%$ UR; $9 \pm 1{ }^{\circ} \mathrm{C}$ e $80 \pm 5 \%$ UR; $6 \pm 1{ }^{\circ} \mathrm{C}$ e $80 \pm 5 \%$ UR; $3 \pm 1{ }^{\circ} \mathrm{C}$ e $80 \pm 5 \%$ UR. Os melões foram armazenados em lotes com 50 unidades por tratamento, permitindo que amostras com seis frutos (três repetições com dois frutos cada) fossem tomadas a cada três dias para os melões armazenados a $22^{\circ} \mathrm{C}$ e a cada cinco dias para os refrigerados. Os frutos foram retirados de cada temperatura de armazenamento e imediatamente avaliados quanto à coloração, à firmeza da polpa, os teores de sólidos solúveis e de acidez titulável, atividade das enzimas peroxidase, polifenoloxidase, poligalacturonase, pectinametilesterase e perda de massa fresca.

A coloração da polpa foi avaliada utilizandose de colorímetro Minolta CR400, expressa em luminosidade, ângulo Hue e cromaticidade. Foi feita uma leitura de cada metade da polpa após o corte longitudinal do fruto. A firmeza da polpa foi avaliada na região equatorial dos frutos, em lados opostos, com uma leitura feita de cada lado, usando-se penetrômetro FT 327 com ponteira de $8 \mathrm{~mm}$, sendo os resultados expressos em Newtons (N). Os teores de sólidos solúveis e de acidez titulável foram determinados segundo AOAC (1997), sendo que os resultados dos teores de sólidos solúveis foram expressos em ${ }^{\circ}$ Brix e os de acidez titulável foram expressos em gramas de ácido cítrico $100 \mathrm{~g}^{-1}$ de polpa. A atividade das enzimas peroxidase e polifenoloxidase foi determinada segundo MATSUNO \& URITANI (1972). Para a atividade da enzima peroxidase pesou-se dez gramas da polpa de melão, a qual foi adicionada $20 \mathrm{~mL}$ de tampão fosfato de potássio $(0,2 \mathrm{M})$. Homogeneizou-se por 1 minuto e em seguida centrifugou-se a $11.655 \mathrm{xg}$ por 10 minutos a $4^{\circ} \mathrm{C}$. A atividade foi determinada no sobrenadante, onde se pipetou em tubos de ensaio: $0,5 \mathrm{~mL}$ de solução de peróxido de hidrogênio $\left(\mathrm{H}_{2} \mathrm{O}_{2}\right) ; 0,5 \mathrm{~mL}$ de solução de fenol; $0,6 \mathrm{~mL}$ da solução tampão fosfato de potássio e $0,4 \mathrm{~mL}$ do extrato. Os tubos foram aquecidos em banhomaria a $30^{\circ} \mathrm{C}$ por 5 minutos. Em seguida, adicionou-se $2 \mathrm{~mL}$ de álcool etílico a $95 \%$. A leitura da absorbância foi feita em espectrofotômetro a $505 \mathrm{~nm}$. Os resultados foram expressos em $\mu \mathrm{mol}$ de $\mathrm{H}_{2} \mathrm{O}_{2}$ degradado $\mathrm{g}^{-1} \mathrm{~min}^{-1}$. Para a atividade da polifenoloxidase utilizou-se o mesmo extrato preparado para a determinação da atividade da enzima peroxidase. Foi pipetado em cada tubo de ensaio: $0,5 \mathrm{~mL}$ da solução de fenol e $1,0 \mathrm{~mL}$ de extrato. Posteriormente, os tubos foram aquecidos em banhomaria a $30^{\circ} \mathrm{C}$, por 5 minutos. Em seguida, adicionou-se $2 \mathrm{~mL}$ de álcool etílico a $95 \%$. A leitura da absorbância foi realizada em espectrofotômetro a $420 \mathrm{~nm}$. Os resultados foram expressos em $\mu \mathrm{mol}$ de fenol degradado $\mathrm{g}^{-1}$ $\min ^{-1}$. A atividade da enzima poligalacturonase foi estabelecida de acordo com GHAZALI \& LEONG (1987), onde se pesou cinco gramas de polpa de melão, que foi homogeneizada por 30 segundos, com $30 \mathrm{~mL}$ de tampão de acetato de sódio $(0,1 \mathrm{M}) \mathrm{pH} 6,0$ contendo $1,0 \%$ de polivinilpirrolidona (PVP) e $0,5 \mathrm{M}$ de $\mathrm{NaCl}$. Centrifugou-se a $26.223 \times$ g por 30 minutos a $4^{\circ} \mathrm{C}$, obtendo-se o extrato enzimático. A atividade foi 
determinada através da reação de $3,0 \mathrm{~mL}$ do extrato enzimático com $3,0 \mathrm{~mL}$ de ácido poligalacturônico (1\%), em tampão de acetato de sódio $(0,1 \mathrm{M}), \mathrm{pH} 5,0$ incubada a $27^{\circ} \mathrm{C}$ durante 3 horas. A reação foi paralisada com a imersão dos tubos em água fervendo, por 5 minutos. Resfriaram-se os tubos no gelo. A avaliação da atividade foi feita reagindo-se $0,2 \mathrm{~mL}$ da amostra contida nos tubos; $1,3 \mathrm{~mL}$ de água destilada e $1 \mathrm{~mL}$ da solução de 3,5 dinitro salicílico (DNS). No branco adicionou-se $1,5 \mathrm{~mL}$ de água destilada e $1 \mathrm{~mL}$ de DNS. Agitaram-se os tubos. Ferveu-se em banho-maria por 5 minutos e em seguida resfriou-se em gelo por 3 minutos. Acrescentouse $7,5 \mathrm{~mL}$ de água destilada, agitou-se e fez-se leitura em espectrofotômetro a 540nm. Uma unidade de PG foi definida como a quantidade de enzima que produziu $1 \mu \mathrm{mol}$ de grupos redutores por grama de enzima, em 3 horas. A atividade específica foi expressa como unidades de enzima por grama por hora (UAE $\mathrm{g}^{-1}$ $\left.\mathrm{h}^{-1}\right)$. E a atividade da enzima pectinametilesterase foi determinada conforme HULTIN et al. (1966) e RATNER et al. (1969), onde utilizou-se o extrato preparado para a determinação da atividade da PG. Pipetou-se $5 \mathrm{~mL}$ do extrato em béquer $(40 \mathrm{~mL})$, adicionou-se $25 \mathrm{~mL}$ de pectina cítrica. Titulou-se durante 10 minutos com $\mathrm{NaOH}$ a $0,01 \mathrm{M}$ e os resultados foram expressos em UAE $g^{-1} h^{-1}$. A perda de massa fresca foi expressa em porcentagem, considerando-se a diferença entre o peso inicial do fruto e aquele obtido a cada intervalo de tempo de amostragem, por meio de pesagem em balança Marte $^{\circledR}$, com capacidade para 40 quilos.

$\mathrm{O}$ delineamento utilizado foi o inteiramente casualizado. Para a temperatura de $22^{\circ} \mathrm{C}$, foram realizadas seis amostragens + amostra inicial e, para as demais temperaturas, foram feitas cinco amostragens + amostra inicial. Utilizaram-se três repetições com dois frutos cada, para cada tratamento. Os resultados obtidos foram submetidos à análise de variância para regressão polinomial e efeitos principais, bem como o desdobramento da interação tempo de armazenamento $\mathrm{x}$ temperaturas, a fim de estudar os efeitos do tempo de armazenamento dentro de cada temperatura (BANZATTO \& KRONKA, 2008).

\section{RESULTADOS E DISCUSSÃO}

A coloração da polpa manteve-se mais clara nos frutos sob refrigeração, principalmente nos armazenados a $6^{\circ} \mathrm{C}$, que apresentaram maiores valores $(67,47)$ de luminosidade. Os frutos submetidos a $3^{\circ} \mathrm{C}$ apresentaram valor médio de 65,60 e os a $9^{\circ} \mathrm{C}$, média de 65,82 . Os melões a $22^{\circ} \mathrm{C}$ apresentaram os menores valores $(63,69)$, indicando que a polpa encontrava-se mais escurecida em relação aos frutos armazenados sob refrigeração, o que pode ser verificado por essa variável. Não houve influência significativa $(P>0,05)$ das temperaturas testadas ao longo do período de armazenamento.

Os valores de cromaticidade diminuíram em todas as temperaturas testadas (Figura 1), porém, nos melões armazenados $a 3^{\circ} \mathrm{C}$, a reta apresentou maior ângulo em relação ao eixo das ordenadas, indicando que houve manutenção dos pigmentos. $\mathrm{O}$ aumento da temperatura acarreta no aumento da velocidade das reações, fazendo com que a síntese de pigmentos seja maior.

Houve redução mais intensa nos valores do ângulo Hue da polpa dos frutos ao longo do período de armazenamento nos melões armazenados a $9^{\circ} \mathrm{C}$ e $22^{\circ} \mathrm{C}$ (Figura 1). Essa redução indica que as temperaturas mais elevadas propiciaram o amadurecimento rápido dos frutos, cujas polpas tornaram-se mais amareladas ao longo do período.

A atividade da peroxidase (POD) dos frutos aumentou em todos os tratamentos durante $\mathrm{o}$ armazenamento, sendo as maiores médias obtidas nos melões armazenados a $3^{\circ} \mathrm{C}$ (Figura 2). Isso

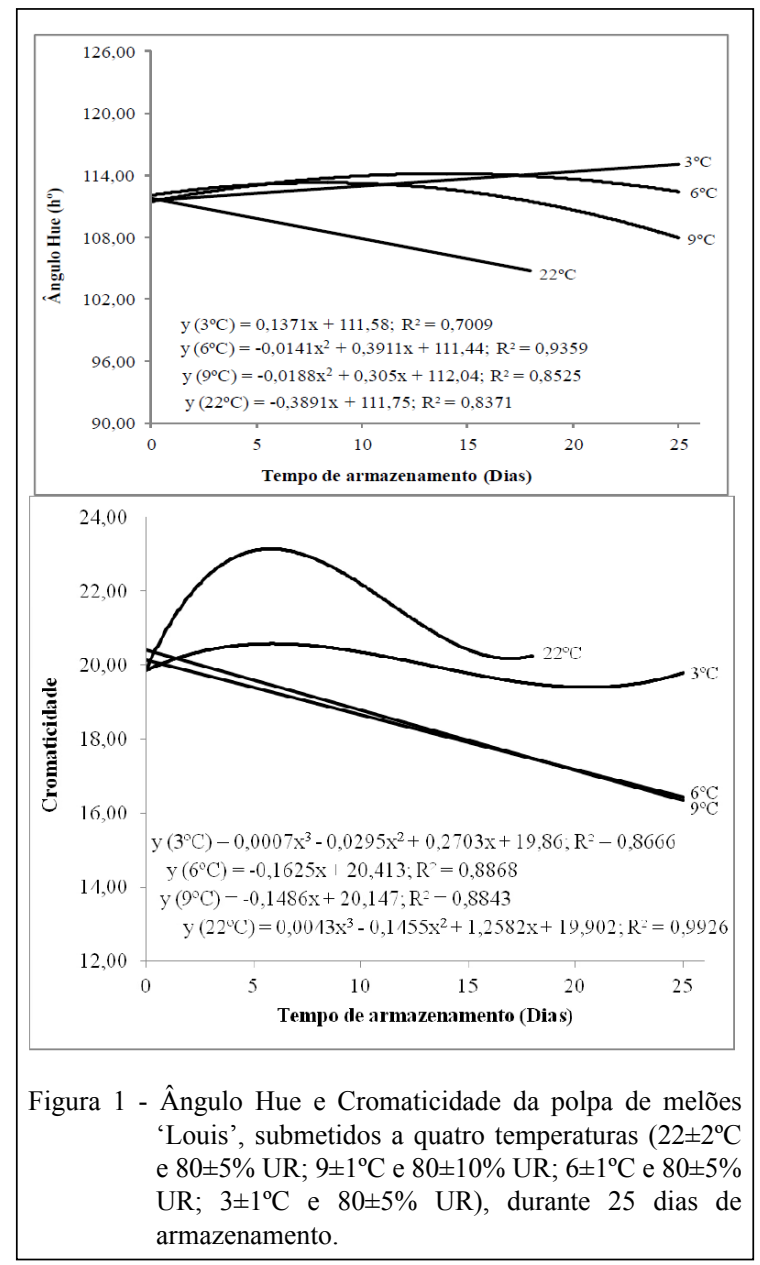




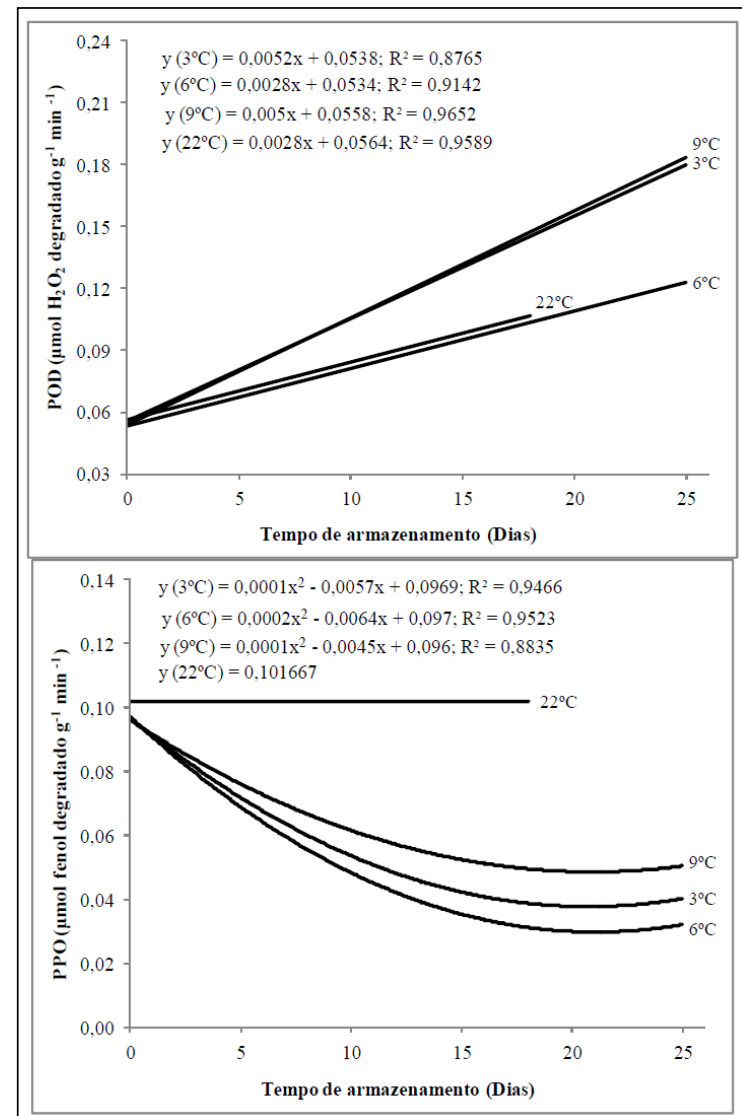

Figura 2 - Atividade da peroxidase (POD) e da polifenoloxidase (PPO), da polpa de melões 'Louis' submetidos a quatro temperaturas $\left(22 \pm 2^{\circ} \mathrm{C}\right.$ e $80 \pm 5 \%$ UR; $9 \pm 1^{\circ} \mathrm{C}$ e $80 \pm 5 \%$ UR; $6 \pm 1^{\circ} \mathrm{C}$ e $80 \pm 5 \%$ UR; $3 \pm 1^{\circ} \mathrm{C}$ e $80 \pm 5 \%$ UR), durante 25 dias de armazenamento.

pode ser indicativo da ocorrência de oxidações, devido aos danos causados pela baixa temperatura, porém visualmente não se detectaram injúrias.

$\mathrm{O}$ aumento na atividade da POD pode estar relacionado com a diminuição nos valores de luminosidade, sobretudo nos frutos armazenados a $22^{\circ} \mathrm{C}$, que apresentaram polpa mais escurecida, devido à atividade dessa enzima, uma vez que o escurecimento ou descoloração dos tecidos são oriundos de reações catalisadas por essa enzima (LAURENTI \& CLEMENTE, 2005). CHISARI et al. (2009) observaram redução na atividade da POD em melões 'Gália' durante o armazenamento, diferente do encontrado neste trabalho.

A atividade da polifenoloxidase (PPO) diminuiu nos frutos armazenados sob $3^{\circ} \mathrm{C}, 6^{\circ} \mathrm{C}$ e $9^{\circ} \mathrm{C}$ (Figura 2), o que explica a ausência de escurecimento da polpa dos melões armazenados nas temperaturas mais baixas, devido à redução na velocidade das reações enzimáticas. Essa tendência também foi encontrada por CHISARI et al. (2009), que verificaram diminuição progressiva na atividade da PPO durante o amadurecimento em melões da cv. 'Gália'.

Ocorreu redução na firmeza dos melões ao longo do armazenamento (Figura 3), e as menores médias foram verificadas nos frutos armazenados a $9^{\circ} \mathrm{C}$ e a $22^{\circ} \mathrm{C}$, indicando que o amadurecimento foi mais acelerado que nas demais temperaturas, já que o amolecimento da polpa em melões é uma tendência natural, devido ao amadurecimento e ao armazenamento. Os frutos armazenados a $6^{\circ} \mathrm{C}$ apresentaram diminuição menos intensa dos valores de firmeza até o $25^{\circ}$ dia, indicando que o processo de amadurecimento ocorreu mais lentamente, visto que, em temperaturas mais baixas, ocorre menor atividade das enzimas relacionadas à degradação da parede celular, como a poligalacturonase e a pectinametilesterase (SOUZA et al., 2006).

Houve aumento gradual na perda de massa durante o armazenamento (Figura 3), que

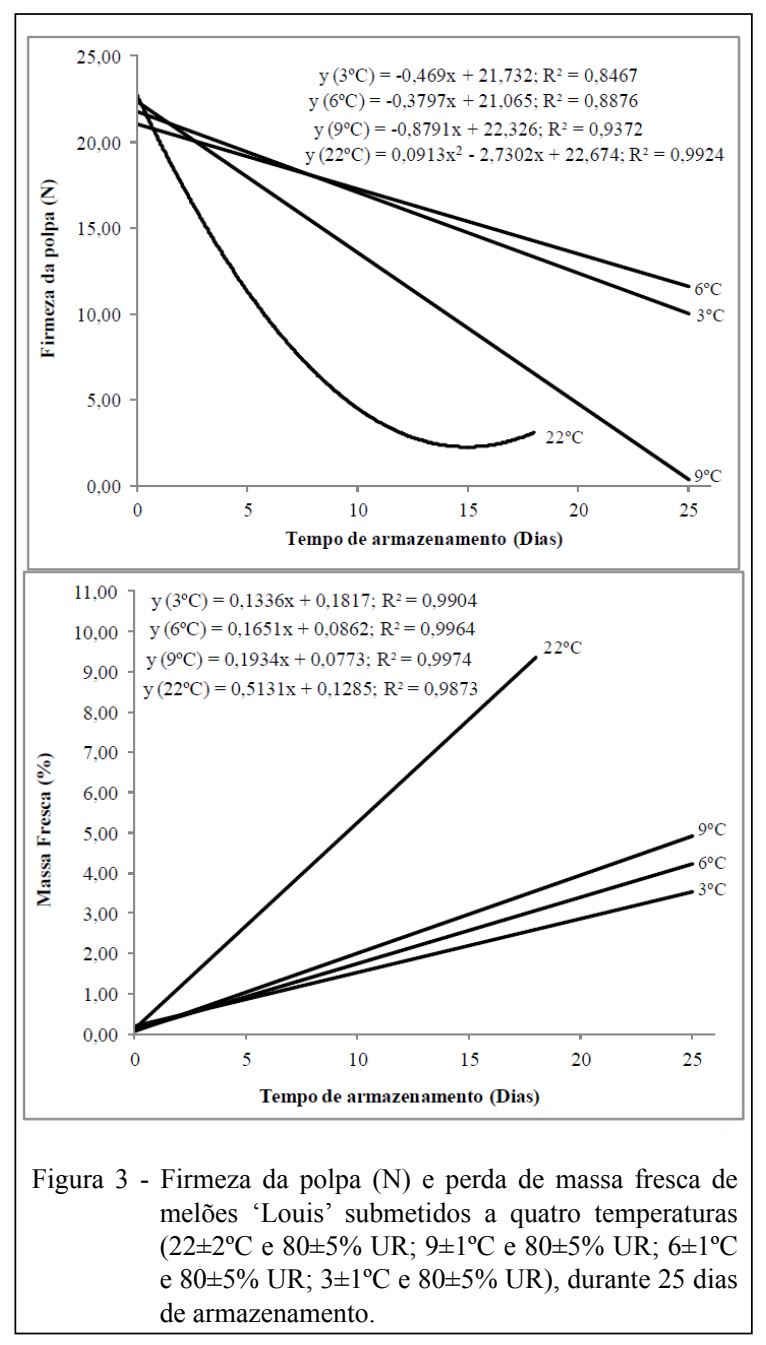

Ciência Rural, v.45, n.11, nov, 2015. 
foi maior nos frutos armazenados a $22^{\circ} \mathrm{C}$, e os armazenados a $3^{\circ} \mathrm{C}, 6^{\circ} \mathrm{C}$ e $9^{\circ} \mathrm{C}$ perderam massa fresca com menor intensidade. Isso ocorre por que, quanto menor a temperatura de armazenamento, menor a taxa respiratória, logo, menor será a transpiração, e, consequentemente, menor a perda de massa (DAMIANI et al., 2008).

A atividade da poligalacturonase $(\mathrm{PG})$ aumentou com o tempo de armazenamento, nos frutos armazenados a $3^{\circ} \mathrm{C}$ e $9^{\circ} \mathrm{C}$ (Figura 4), coincidindo com decréscimos nos valores de firmeza. Nos frutos armazenados a $6^{\circ} \mathrm{C}$, a atividade se manteve estável, podendo estar relacionado com a menor inclinação da reta dos valores de firmeza, nesta temperatura. Os frutos armazenados a $22^{\circ} \mathrm{C}$ também apresentaram aumento na atividade da $\mathrm{PG}$, porém com valores mais elevados, confirmando que os melões estavam mais moles, uma vez que o amolecimento está relacionado com o aumento da

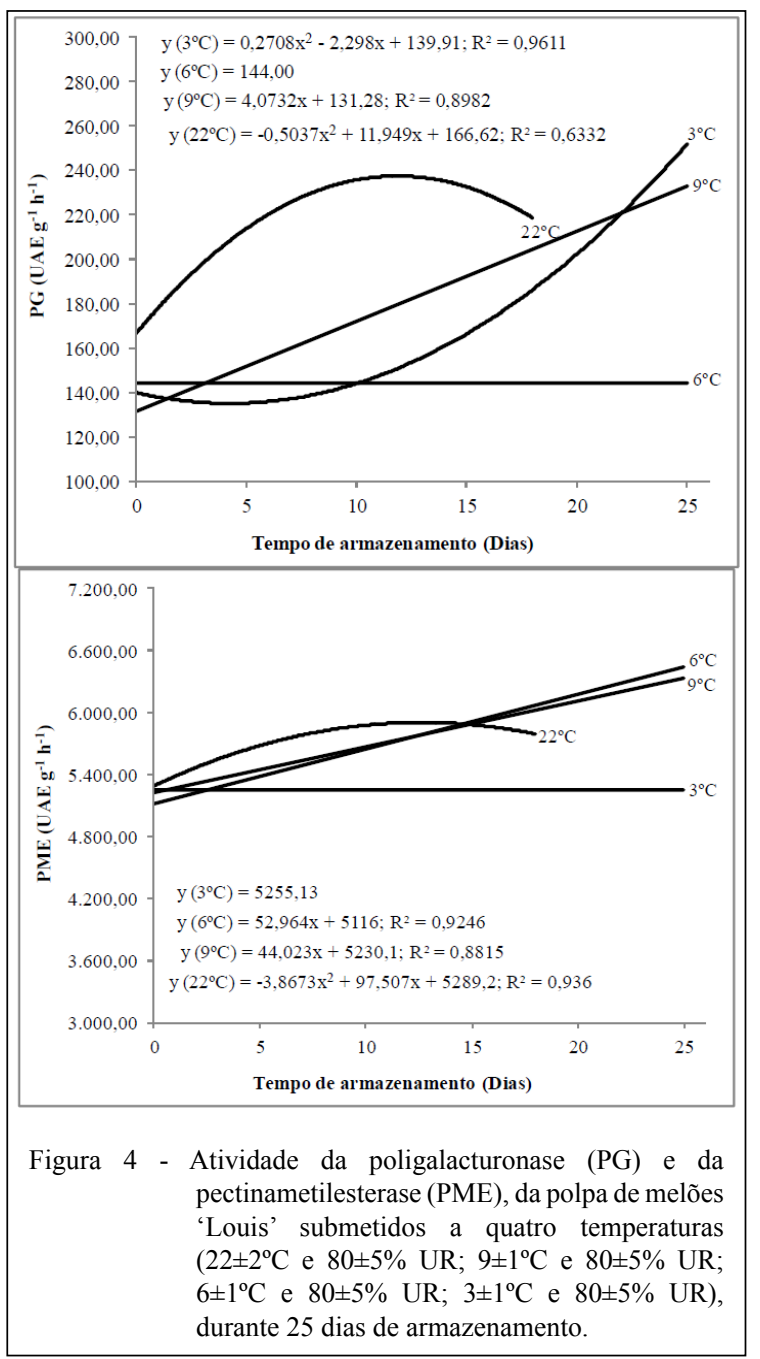

atividade de hidrolases tais como a poligalacturonase (PG) e pectinametilesterase (PME), durante o armazenamento (SOUZA et al., 2006).

A atividade da pectinametilesterase (PME) também aumentou linearmente com o tempo de armazenamento nos frutos armazenados a $6^{\circ} \mathrm{C}$ e a $9^{\circ} \mathrm{C}$ (Figura 4). Nos frutos armazenados a $3^{\circ} \mathrm{C}$, a ação da enzima se manteve estável durante todo o armazenamento e, nos melões a $22^{\circ} \mathrm{C}$, a atividade foi mais alta, relacionando-se com a diminuição acentuada nos valores da firmeza. Isto foi diferente do relatado por SOUZA et al. (2008), que não detectou atividade desta enzima em melões 'Charentais'.

Os teores de sólidos solúveis diminuíram ao longo do período de armazenamento, exceto nos frutos armazenados a $6^{\circ} \mathrm{C}$, onde os valores apresentaram tendência em se manterem constantes (Figura 5). Isso pode estar ligado com a manutenção da firmeza nessa temperatura, indicando também que o processo de amadurecimento ocorreu mais lentamente.

Segundo SOUZA et al. (2008), essa diminuição nos teores de sólidos solúveis durante o armazenamento pode ser devida ao consumo de açúcares pelo processo respiratório dos frutos. Além disso, temperaturas mais elevadas podem acarretar na aceleração da velocidade das reações, fazendo com que a taxa respiratória aumente e os açúcares sejam consumidos no processo.

Verificou-se diminuição nos valores da acidez da polpa dos melões, durante o armazenamento (Figura 5). Essa diminuição nos teores de acidez titulável, sobretudo mais acentuada nos melões armazenados nas temperaturas mais elevadas, como a $22^{\circ} \mathrm{C}$, indica que os ácidos podem ter sido consumidos no processo respiratório. O observado não é concordante com o relatado por MORAIS et al. (2009). Esses autores indicaram aumento na acidez de melões ('Gália' 'Solar King', 'Charentais' 'Aura Prince', 'Orange Flesh' 'AF1749') até o 14을 dia de armazenamento, com posterior redução até o $28^{\circ}$ dia, a $9^{\circ} \mathrm{C}$ e $80 \%$ UR.

\section{CONCLUSÃO}

Melões 'Louis' apresentaram vida útil de 25 dias a $3^{\circ} \mathrm{C}, 6^{\circ} \mathrm{C}$ e $9^{\circ} \mathrm{C}$ e de 18 dias quando armazenados a $22^{\circ} \mathrm{C}$. Os frutos armazenados a $6^{\circ} \mathrm{C}$ foram os que apresentaram maiores teores de sólidos solúveis, bem como menor atividade das enzimas peroxidase e poligalacturonase. 


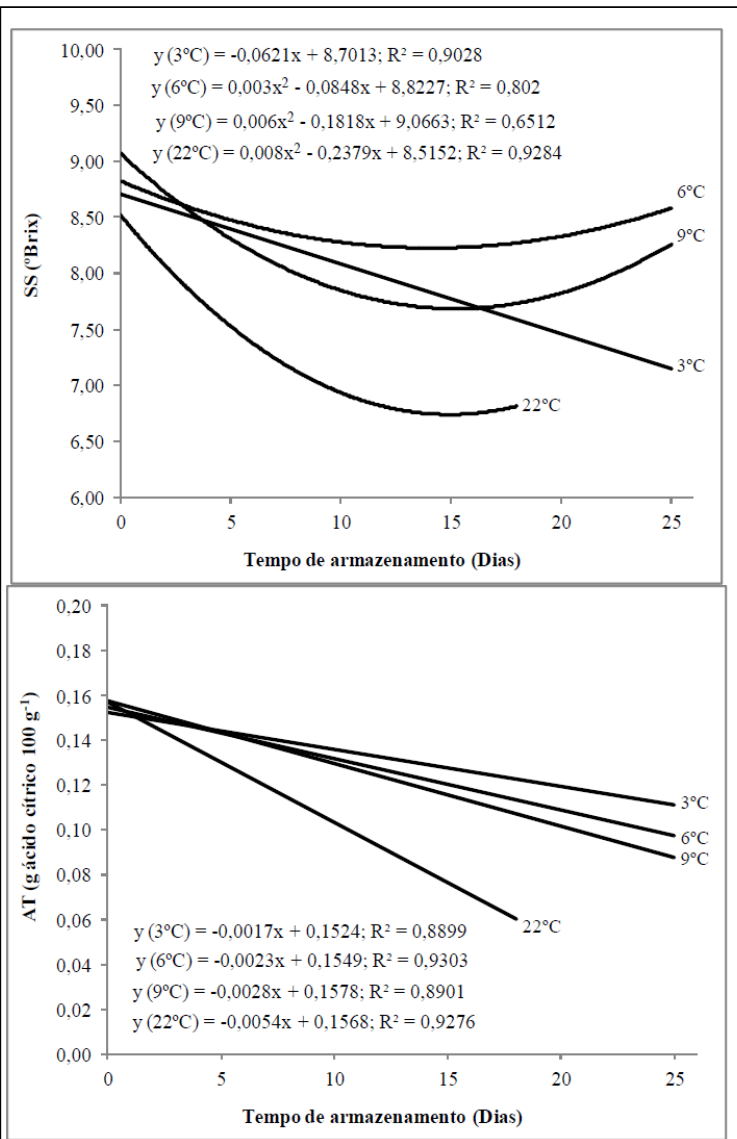

Figura 5 - Teores de sólidos solúveis ( ${ }^{\circ}$ Brix) e de acidez titulável ( $\mathrm{g}$ ác. cítrico $100 \mathrm{~g}^{-1}$ ) da polpa de melões 'Louis' submetidos a quatro temperaturas $\left(22 \pm 2^{\circ} \mathrm{C}\right.$ e $80 \pm 5 \%$ UR; $9 \pm 1^{\circ} \mathrm{C}$ e $80 \pm 5 \%$ UR; $6 \pm 1^{\circ} \mathrm{C}$ e $80 \pm 5 \%$ UR; $3 \pm 1^{\circ} \mathrm{C}$ e $80 \pm 5 \%$ UR), durante 25 dias de armazenamento.

\section{AGRADECIMENTOS}

Os autores agradecem à Fundação de Amparo à Pesquisa do Estado de São Paulo (FAPESP), processos 2010/10615-4 e 2010/12829-1 pelo apoio financeiro.

\section{REFERÊNCIAS}

AOAC (ASSOCIATION OF OFFICIAL ANALYTICAL CHEMISTS). Official methods of analysis of the Association of Official Analytical Chemists International. 16.ed. Washington: Patrícia Cunniff, 1997. v.2, cap.37.

BANZATTO, D.A.; KRONKA, S. do N. Experimentação Agrícola. 4.ed. Jaboticabal: Funep, 2008. 237p.

CHISARI, M. et al. Ripening stage influenced the expression of polyphenol oxidase, peroxidase, pectin methylesterase and polygalacturonase in two melon cultivars. International Journal of Food Science and Technology, v.44, p.940946, 2009. Disponível em: <http://dx.doi.org/10.1111 /j.1365-2621.2008.01735.x>. Acesso em: 20 nov. 2013. doi:10.1111/j.1365-2621.2008.01735.x.
CHITARRA, M.I.F.; CHITARRA, A.B. Pós-colheita de frutos e hortaliças: fisiologia e manuseio. Lavras: UFLA, 2005. 785p.

DAMIANI, C. et al. Influência de diferentes temperaturas na manutenção da qualidade de pequi minimamente processado. Ciência e Agrotecnologia, v.32, n.1, p.203-212, 2008. Disponível em: <http:// dx.doi.org/10.1590/S1413-70542008000100030>. Acesso em: 15 nov. 2013. doi:10.1590/S1413-70542008000100030.

FILGUEIRAS, H.A.C. et al. Colheita e manuseio pós-colheita. In: ALVES, R.E. Melão: pós-colheita. Brasília: EMBRAPA, 2000. p.23-41.

GHAZALI, H.N.; LEONG, N. Polygalacturonase activity in starfruit. Food Chemistry, v.24, n.1, p.147-157, 1987. Disponível em: <http:// dx.doi.org/10.1016/0308-8146(87)90046-X>. Acesso em: 3 mar. 2010. doi:10.1016/0308-8146(87)90046-X.

HULTIN, H. O. et al. Pectin methyl esterase of banana. Purification and properties. Journal of Food Science, v.31, n.3, p.320-327, 1966. Disponível em: <http://dx.doi.org/10.1111/j.1365-2621.1966.tb00500. $\mathrm{x}>$. Acesso em: 3 mar. 2010. doi:10.1111/j.1365-2621.1966.tb00500.x.

LAURENTI, C.; CLEMENTE, E. Avaliação da atividade da peroxidase em carambola (Oxalidacia averrhoa) em diferentes estádios de maturação. Acta Scientiarum Agronomy, v.27, n.1, p.159-163, 2005. Disponível em: <http://dx.doi.org/10.4025/actasciagron.v27i1.2159>. Acesso em: 15 dez. 2012. doi:10.4025/actasciagron.v27i1.2159.

LIMA, M.A.C. de. et al. Tratamentos pós-colheita com 1-metilciclopropeno em manga 'Tommy Atkins': efeito de doses e número de aplicações. Revista Brasileira de Fruticultura, v.28, n.1, p.64-68, 2006. Disponível em: <http://dx.doi.org/10.1590/S010029452006000100019>. Acesso em: 14 fev. 2013. doi:10.1590/S010029452006000100019 .

MATSUNO, H.; URITANI, I. Physiological behavior peroxidase isozynes in sweet potato root tissure injuried by cuting or black rot. Plant and Cell Physiology, v.13, n.6, p.1091-1101, 1972. Acesso em: 3 mar. 2010 .

MORAIS, P.L.D. et al.Avaliação das tecnologias pós-colheita utilizadas e da qualidade de melões nobres produzidos para exportação. Ciência e Tecnologia de Alimentos, v.29, n.1, p.214-218, 2009. Disponível em: <http://dx.doi.org/10.1590/S0101-20612009000100033>. Acesso em: 20 out. 2013. doi:10.1590/S0101-20612009000100033.

MOREIRA, S.R. et al. Melão (Cucumis melo L.). 2009. Disponível em: <http://www.infobibos.com/Artigos/2009 3/melao/index.htm>.

RATNER, A. et al. Activity of pectin esterase and cellulase in the abcission zone of citrus leaf explants. Plant Physiology, v.44, n.12, p.1717-1723, 1969. Disponível em: <http://dx.doi.org/10.1104/ pp.44.12.1717>. Acesso em: 5 abr. 2010. doi:10.1104/pp.44.12.1717.

SOUZA, P. A. et al. Armazenamento refrigerado de melão 'Gália' 'Solarking' sob atmosfera modificada. Caatinga, v.19, n.4, p.377382, 2006. Acesso em: 23 nov. 2013.

SOUZA, P. A. et al. Conservação pós-colheita de melão 'Charentais' tratado com 1-MCP e armazenado sob refrigeração e atmosfera modificada. Horticultura Brasileira, v.26, p.464-470, 2008. Disponível em: <http://dx.doi.org/10.1590/S0102-05362008000400008>. Acesso em: 30 maio. 2013. doi:10.1590/S0102-05362008000400008.

TAKII SEED. Melão hibrido Louis. Disponível em: <http://www. takii.com.br/melaolouis.html >. Acesso em: 6 jun. 2010. 